\title{
Cold Deep-drawing of AZ31 Magnesium Alloy Sheet under Controlled Forming Motion Using Servo Press Machine
}

\author{
Masahiro Ohkawa ${ }^{1,2, *}$, Akito Takasaki ${ }^{3}$ \\ ${ }^{1}$ Graduate School of Engineering and Science, Shibaura Institute of Technology, Japan \\ ${ }^{2}$ Plastic Forming Engineering Unit, Polytechnic University, Japan \\ ${ }^{3}$ Department of Engineering Science and Mechanics, Shibaura Institute of Technology, Japan
}

Copyright $\subseteq 2016$ by authors, all rights reserved. Authors agree that this article remains permanently open access under the terms of the Creative Commons Attribution License 4.0 International License

\begin{abstract}
The deep drawing of an AZ31 magnesium alloy sheet with a commonly used metal mold by three kinds of drawing motions (crank, vibration, and step-by-step motion) was performed, and the effect of drawing motions on the forming performances of the alloy sheet was investigated. For all the forming motions, the limited drawing ratio $(L D R)$ reached was 1.25 , and crack formation was limited at the flange part with the rolling direction. The vibration motion, which has a bigger shoulder region, cause greater lattice distortion of the side wall than other motions and the lattice strain for vibration motion increased from the bottom to the side wall of the sheet after drawing, whereas the heteromorphic histories for other motions were different. The crystallite size was largest at the bottom of the sheet for all the forming motions. However, it decreased at the shoulder part of the sheet and also at the side wall. The crystalline grains structure was not affected by drawing motions. It was found that the drawing motions affected the state of stress-relaxation after drawing.
\end{abstract}

Keywords AZ31 Magnesium Alloy, Deep Drawing, Servo Press, LDR, Room Temperature Forming

\section{Introduction}

Magnesium ( $\mathrm{Mg}$ ) alloys are widely used to manufacture products such as automobiles, trains, aircrafts, and in many other industries ${ }^{[1-3]}$. They have received a lot of attention, especially from the transportation industry because of their high recyclability and lightweight, which lowers $\mathrm{CO}_{2}$ emission and improve fuel consumption ${ }^{[4]}$. However, they are known to be poor in ductility at room temperature ${ }^{[5-7]}$, so that $\mathrm{Mg}$ alloys are usually formed at temperatures between $250^{\circ} \mathrm{C}$ and $400^{\circ} \mathrm{C}$. Zhang et all ${ }^{[8]}$ suggested that rolled $\mathrm{Mg}$ alloy sheets had good deep drawing formability at a forming temperature range of $105-170{ }^{\circ} \mathrm{C}$ with limited drawing ratio $(L D R)$ up to 2.6. Recently, mechanical or ultrasonic vibration has been added to the process to improve $L D R$ for steels and aluminums sheets ${ }^{[9-11]}$. Because of the pause gap in the middle of the drawing process, the elastic strain partially changes into plastic strain. Then, the strains are dispersed, and stress concentration is delayed, which helps improve the forming limit ${ }^{[12]}$. In addition to the conventional mold, which is used during drawing. The servo press controls the slide position and speed in each stroke [13-14]. Step-by-step motion has also been added to the process for steel. However, there is no investigation on such processes for Mg alloys.

In this study, using the servo press machine, the effect and usefulness of the vibration motion and the step-by-step motion drawing on the forming performances of commercially available $\mathrm{Mg}$ alloy (AZ31-O) at R.T. are analyzed.

\section{Materials and Methods}

\subsection{NC Servo Pressing Machine and Deep Drawing Mold}

Fig. 1 shows a servo pressing machine, made by Amada Co. Ltd., Japan, model number SDE4514, with a maximum load of $450 \mathrm{kN}$.

Fig. 2 shows a structural schematic drawing of the deep drawing mold attached with a work and a die. The mold consists of a punch whose diameter is $60 \mathrm{~mm}$ (punch nose radius is $10 \mathrm{~mm}$ ), a blank holder at a lower side and an upper die whose inner diameter is $62.5 \mathrm{~mm}$ (die nose radius is $10 \mathrm{~mm}$ ). One side clearance between the punch and the die was $1.25 \mathrm{~mm}$. The blankholder force was kept constant at $9 \mathrm{kN}$. Punch load was measured by a strain gauge (model number KFG-1-1-120-D16-11) attached to the punch base. 
The punch stroke was measured using a differential transformer type displacement gauge.

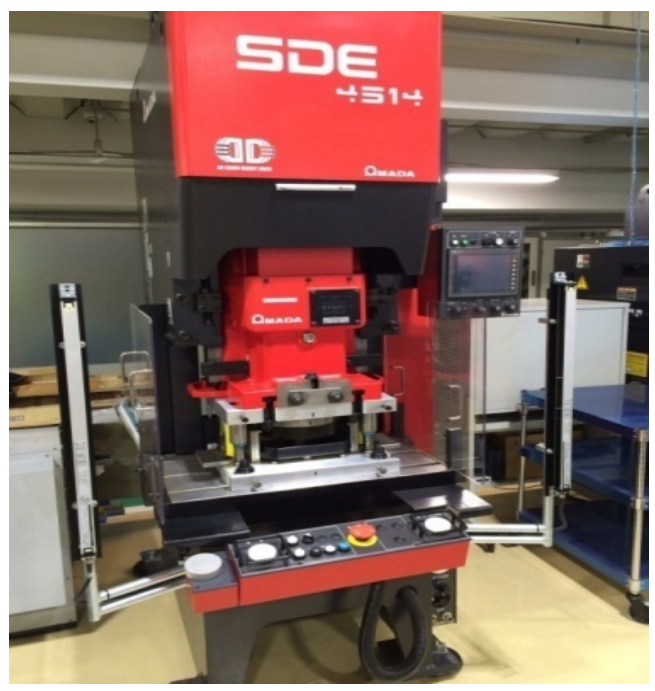

Figure 1. NC servo pressing machine

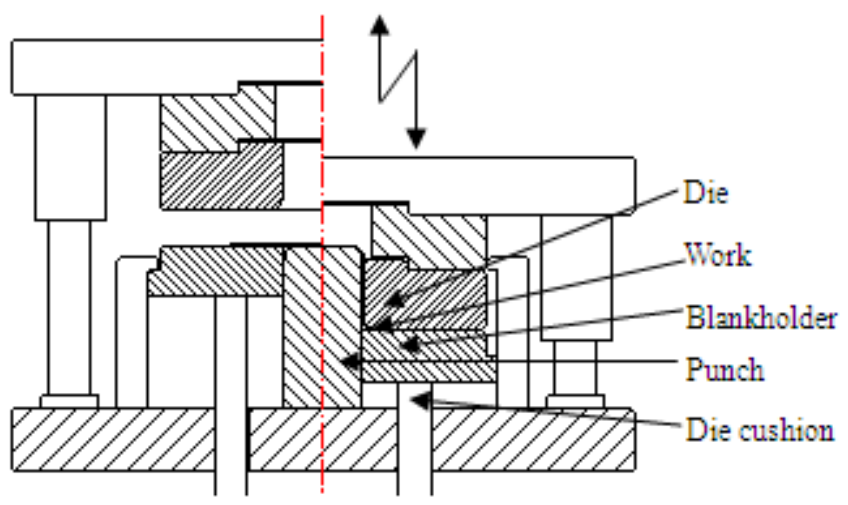

Figure 2. Structural schematic drawing of the deep drawing mold used.

\subsection{Materials}

The material used in this study is a commercially available Mg alloy (AZ31-O), made in OSAKA FUJI Co. Ltd., Japan, with thickness of $0.8 \mathrm{~mm}$. The diameter used drawing ratios of $1.25,1.29,1.33$, and 1.38 . Tables 1 and 2 show the chemical composition and mechanical properties of AZ31-O, respectively. The microstructures of the AZ31 exhibited almost all equiaxed grains, as shown in Fig. 3. The grain size was distributed in the range from $3 \mu \mathrm{m}$ to $20 \mu \mathrm{m}$, as shown in Fig. 3.

Table 1. Chemical composition of AZ31-O alloy [wt\%]

\begin{tabular}{|c|c|c|c|c|c|c|}
\hline Material & $\mathrm{Al}$ & $\mathrm{Zn}$ & $\mathrm{Mn}$ & $\mathrm{Si}$ & $\mathrm{Fe}$ & $\mathrm{Mg}$ \\
\hline AZ31-O & 2.96 & 1.03 & 0.41 & 0.01 & 0.001 & Bal. \\
\hline
\end{tabular}

Table 2. Mechanical properties of AZ31-O alloy

\begin{tabular}{|c|c|c|c|c|}
\hline Material & $\begin{array}{c}\text { Tensile } \\
\text { strength } \\
{[\mathrm{MPa}]}\end{array}$ & $\begin{array}{c}\text { Young's } \\
\text { modulus } \\
{[\mathrm{GPa}]}\end{array}$ & $\begin{array}{c}\text { Breaking } \\
\text { elongation } \\
{[\%]}\end{array}$ & n-value \\
\hline AZ31-O & 271 & 36 & 28.4 & 0.21 \\
\hline
\end{tabular}

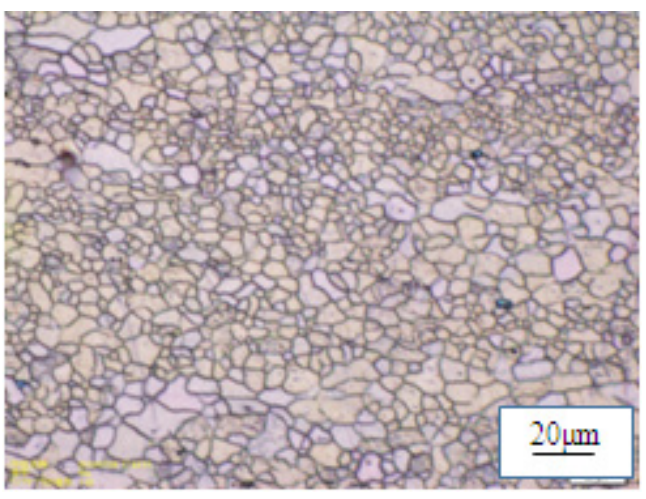

Figure 3. Microstructures of the AZ31-O alloy used in the experiments

\subsection{Drawing Motion}

The drawing motion was controlled by the movement of the die position and the speed of slide that was added on an upper die's mold. Fig. 4 shows a processing diagram for the slide stroke-time. The processing was performed by the combination of upward stroke and downward stroke. The amount of stroke distance was in the range of $0 \mathrm{~mm} \leqq A d$ $\leqq 4 \mathrm{~mm}$ and $0.25 \mathrm{~mm} \leqq D d \leqq 5.5 \mathrm{~mm}$. There were three kinds of drawing motions: crank, vibration, and step-by-step motions. Fig. 5 shows a processing diagram for the slide stroke-time, considering the crank motion. The slide of the crank motion draws a parabola from the top dead center to the bottom dead center of the crank. Fig. 6 shows a processing diagram for the slide stroke-time for the vibration motion. The slide movement causes a vertical motion of the upper die when the slide moves from the top dead center to the bottom dead center. $\Delta D d$ was the difference between $A d$ and $D d$, and the die has fine vibrations if $\Delta D d$ is small. Finally, Fig. 7 shows a processing diagram for the slide stroke-time in the step-by-step motion. The slide movement of the upper die is forced to stop and descend while it works from the top dead center to the bottom dead center. In this case, the motion was set to $A d=0.01 \mathrm{~mm}$ and stop time was set as $1 \mathrm{~s}$. When the movement was small ( $\Delta D d$ became small), the processing time was longer. A Teflon sheet, with thickness of $0.05 \mathrm{~mm}$, was used as a lubricant in this study.

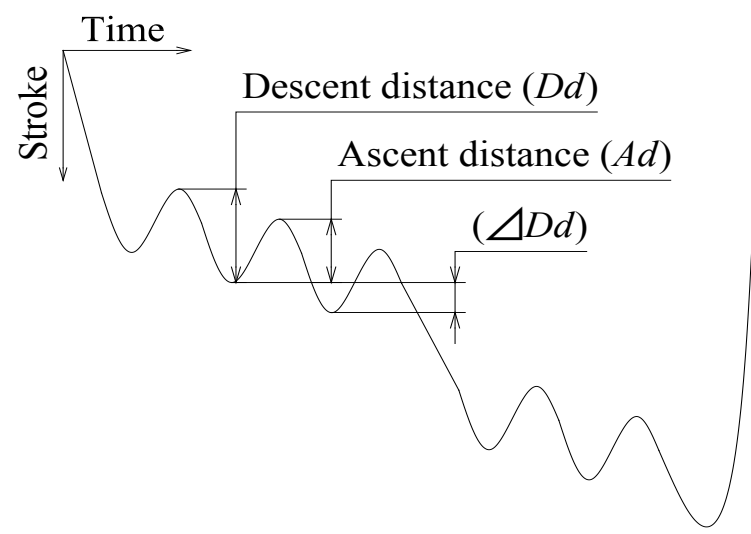

Figure 4. Processing diagram for the slide stroke-time 


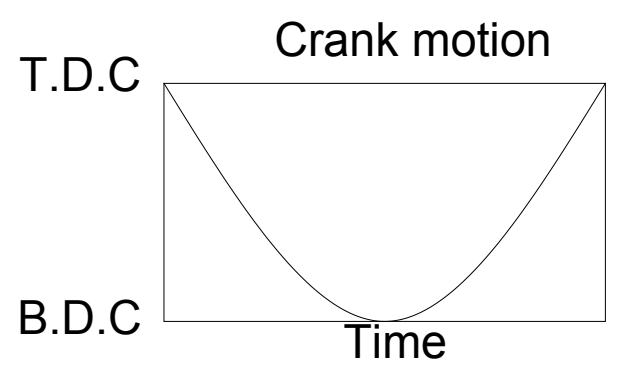

Figure 5. Processing diagram for the slide stroke-time for crank motion

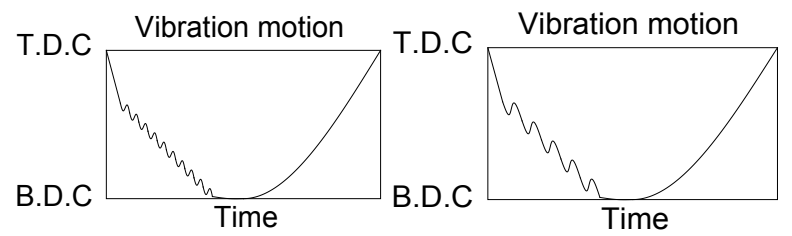

Figure 6. Processing diagram for the slide stroke-time for vibration motion

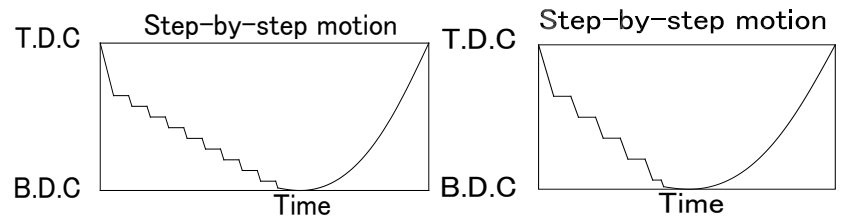

Figure 7. Processing diagram for the slide stroke-time for step-by-step motion

\subsection{Lattice Strain and Crystallite Size}

Lattice parameter of the alloy before and after drawing shows the amount of induced strain and can confirm the deformation hysteresis. The crystallite size estimates crystal grain size and can also confirm the state of the crystal grain structure. Lattice strain and crystallite size can be measured at peak position and at half-width of the peak by an X-ray diffractometer $(\mathrm{XRD})$ measurement ${ }^{[15]}$, which is performed by a Rigaku Ultima IV with $\mathrm{Cu} \mathrm{K} \alpha$ radiation at $40 \mathrm{kV}$ and $20 \mathrm{~mA}$ (scan speed:0.02degree $\mathrm{s}^{-1}$ ), and the sample surfaces are also observed by an optical microscope. For the accurate XRD measurement, the peak positions were corrected using Si powder as the standard sample. Test pieces, whose sizes were $10 \times 10 \mathrm{~mm}$, were cut off from the bottom part, and the shoulder part and side wall of the alloy were processed by crank, vibration and step-by-step motions. Fig. 9 presents a test piece and the positions from which test pieces for XRD were taken.

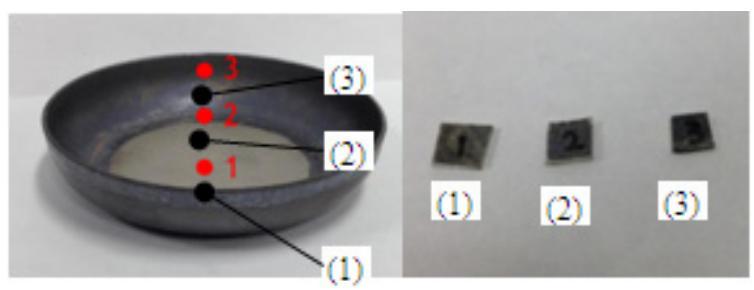

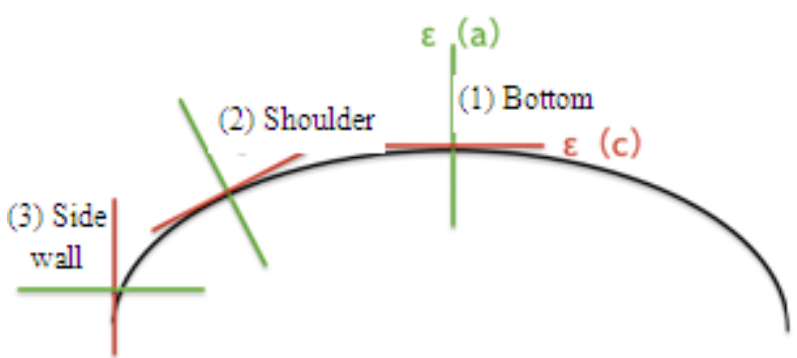

Figure 9. Test piece and the positions from which test pieces for XRD were taken

\section{Results and Discussion}

First, a drawing experiment without vibration or step-by-step motions (only with crank motion) was performed to check the $L D R$. The $L D R$ obtained was 1.25 and it was observed that failure occurred at a flange. Fig. 10 shows a blank state flange and a crack were observed at the flange after drawing. Even if $L D R$ was increased to 1.7, the cracks were limited at that part of the flange.

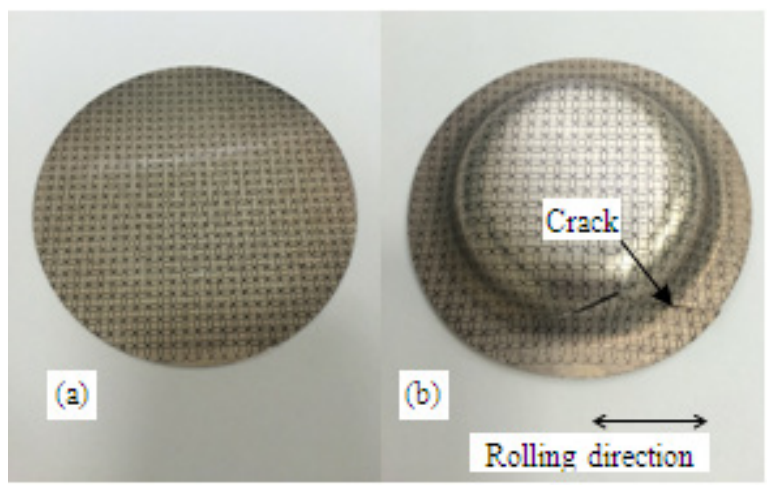

Figure 10. (a) Blank state flange and (b) a crack observed after drawing

The state of stress-relaxation was checked from the punch load-stroke diagram during the vibration and step-by-step motions, when the $L D R$ ratio was 1.25 . Table 4 explains the processing motion conditions. Fig. 11 presents a load-stroke diagram during vibration motion drawing $(\Delta D d=0.25)$. Fig. 12 shows a load-stroke diagram during vibration motion drawing $(\Delta D d=1.0)$. The load remained when $\Delta D d$ was 1.0 and was $9 \%$ of the maximum load, which was smaller than $12 \%$ when $\Delta D d$ was 0.25 . Even though the upward stroke distance was the same, if $\Delta D d$, (downward stroke distance) was higher, a larger gap before the punch that hissed the material would be needed, which also would need more time for the punch to hit the material. Therefore, the time necessary for stress-relaxation increased, and the load that remained in the materials became smaller. 
Table 4. Forming motion conditions

\begin{tabular}{|c|c|c|c|}
\hline Motion type & Speed $\left[\mathrm{min}^{-1}\right]$ & $\operatorname{Ad}[\mathrm{mm}]$ & $\Delta D d[\mathrm{~mm}]$ \\
\hline \multirow{2}{*}{ Crank } & 1 & - & - \\
\hline \multirow{2}{*}{ Vibration } & 10 & - & - \\
\hline Step & 1 & 1.0 & 0.25 \\
$1[\mathrm{sec}]$ & 1 & 1.0 & 1.0 \\
\hline
\end{tabular}

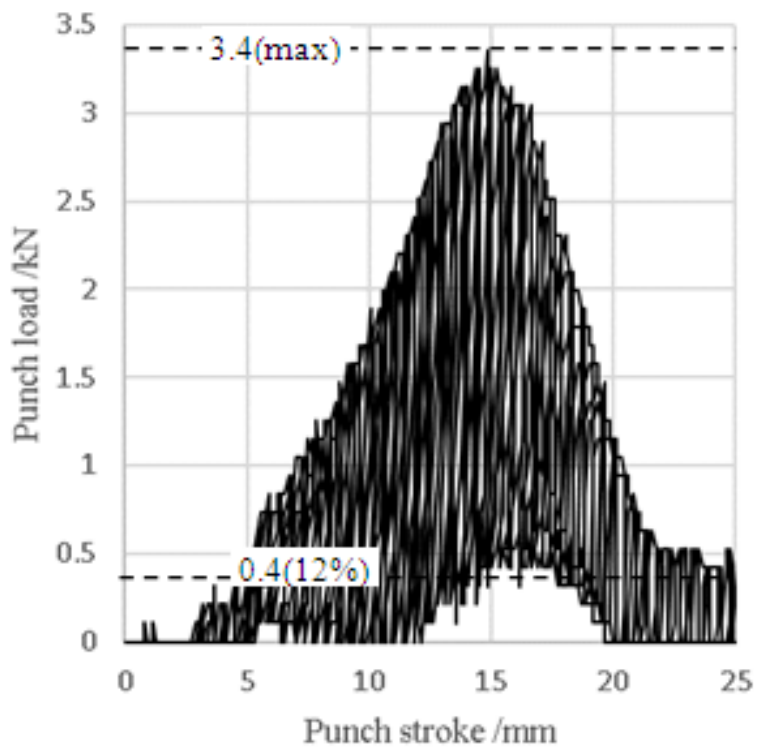

Figure 11. Punch load-stroke diagram $(\Delta D d=0.25$; vibration motion)

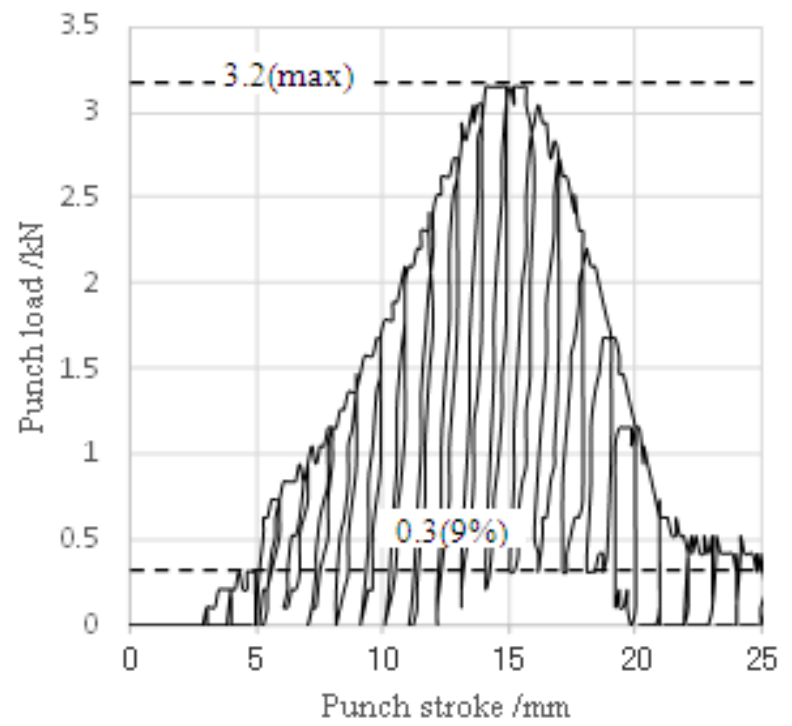

Figure 12. Punch load-stroke diagram $(\Delta D d=1.0$; vibration motion)

Fig. 13 shows a load-stroke diagram during the step-by-step motion processing when $\Delta D d$ was 0.25 , and Fig. 14 shows a load-stroke diagram during the induced motion processing when $\Delta D d$ was 1.0. Step-by-step motion forming induced a small stress-relaxation. Because there was no gap, the load that remained in a punch was large. The load remained in a punch during step-by-step motion when $\Delta D d$ was 1.0 and was $84 \%$ of the maximum load, which was smaller than when $\Delta D d$ was 0.25 . The drawing motions affected the state of stress-relaxation after drawing.

It is found that load remained during vibration motion was much smaller than that during step-by-step motion, suggesting a possibility to improve the limit of deformation of $\mathrm{Mg}$ alloys.

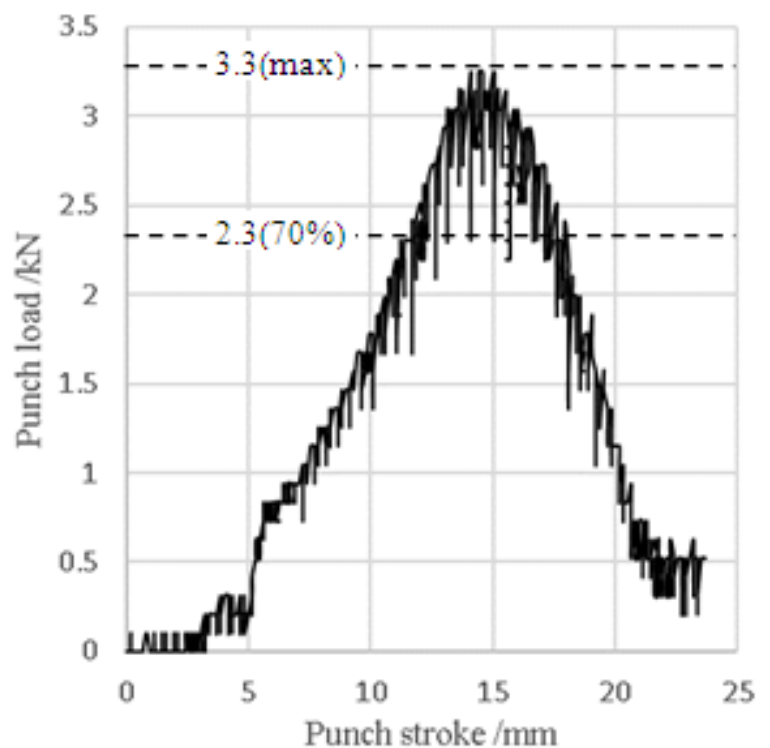

Figure 13. Punch load-stroke diagram $(\Delta D d=0.25$; step-by-step motion $)$

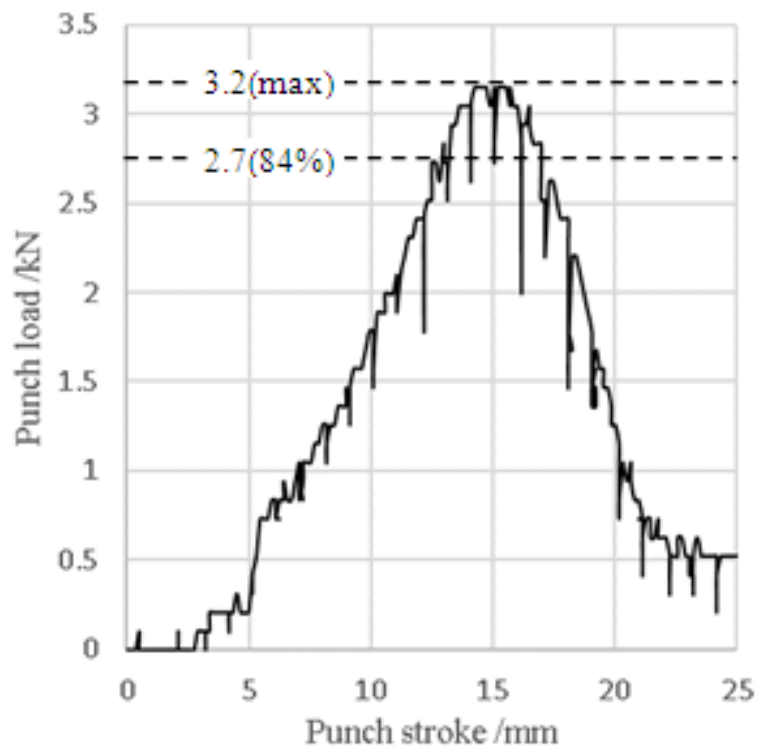

Figure 14. Punch load-stroke diagram $(\Delta D d=1.0$; step-by-step motion)

Crystallite size and lattice strain were calculated using XDR results. It is possible to see the lattice strain of the alloy sheet in Fig. 15 for the different positions shown in Fig. 9. The lattice strain increased from the bottom to the side wall for vibration motion. For the other motions, the lattice strain decreased. A different tendency was seen in lattice strain, which depends on the board direction. Fig. 16 shows the crystallite size of the alloy sheet for the different positions shown in Fig. 9. Crystallite size was largest at the bottom for all the forming motions, which was the same as 
that before the drawing. However, it decreased to about 306 $[\AA]$ at the shoulder part and then to about $284[\AA]$ at the side wall, for the vibration motion. However, the drawing motion might not strongly affect to the crystallite size.

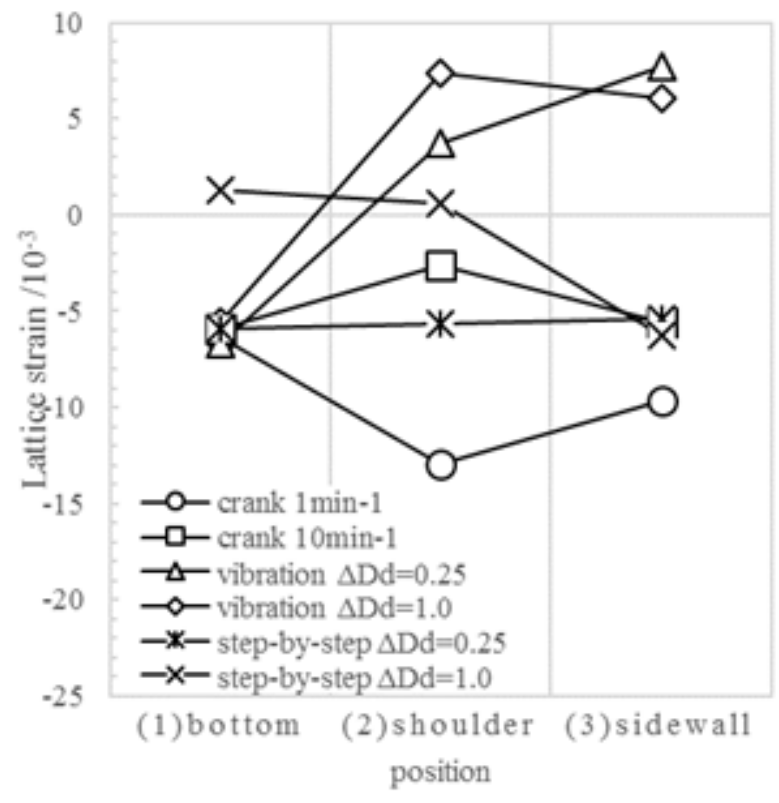

Figure 15. Lattice strain after drawing

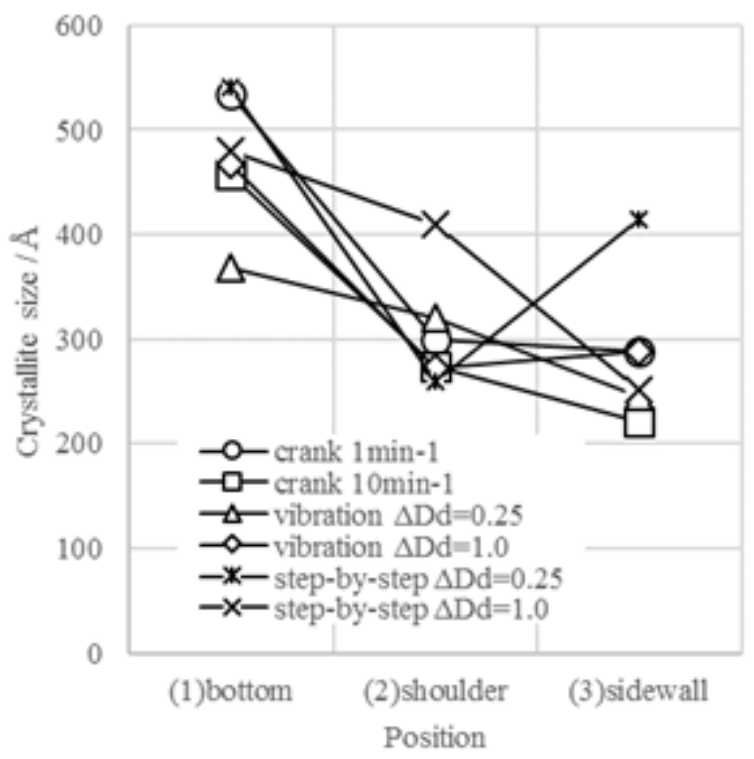

Figure 16. Crystallite size after drawing

\section{Conclusions}

The deep drawing of an AZ31 Mg alloy sheet with a commonly used metal mold by three kinds of drawing motions (crank, vibration, and step-by-step) was performed and the effect of these drawing motions on the forming performance of the alloy sheet was investigated. The results obtained were as follows:

(1) $L D R$ reached was 1.25 and the formation of crack was limited at the flange part with the rolling direction.

(2) The vibration motion, which has a bigger shoulder region, causes greater lattice distortion of the side wall than other motions. As seen in Fig. 15, the lattice strain for vibration motion increased from the bottom to the side wall of the sheet after drawing, whereas the heteromorphic histories for other motions are different. The lattice strain was dependent on the rolling direction of the sheet. The crystallite size was largest at the bottom of the sheet for all the forming motions. However, it decreased to about 306 $[\AA]$ at the shoulder part of the sheet and to about $284[\AA]$ at the side wall. The crystalline grains structure was not affected by the drawing motions.

(3) The load remained when $\Delta D d$ was 1.0 and was $9 \%$ of the maximum load, which was smaller than $12 \%$ when $\Delta D d$ was 0.25 . Also, the load remained in a punch during step-by-step motion when $\Delta D d$ was 1.0 and was $84 \%$ of the maximum load, which was smaller than when $\Delta D d$ was 0.25. The drawing motions affected the state of stress-relaxation after drawing.

\section{REFERENCES}

[1] D. W. James "High damping metals for engineering applications" Mater. Sci. Eng., 4 (1969), pp. 1-8.

[2] B.L. Mordike, and T. Ebert, Materials Science and Engineering A, 302 (2001), pp. 37-45.

[3] H. Tsai C. Liao F. Chen "Die design for stamping a notebook case with magnesium alloy sheets" Journal of Materials Processing Technology, 201 (2008), pp. 247-251.

[4] D.S. Mehta, S.H. Masood, W.Q. Song "Investigation of wear properties of magnesium and aluminum alloys for automotive applications" Journal of Materials Processing Technology, 155-156 (2004), pp. 1526-1531.

[5] Japan Society for Technology of Plasticity (2004), Magnesium processing technique, JAPAN: CORONA, pp. 109-119.

[6] F. K. Chen, T. B. Huang and C. K. Chang "Deep drawing of square cups with magnesium alloy AZ31 sheets" International Journal of Machine Tools and Manufacture, vol. 43(2003), pp. 1553-1559.

[7] Y. Chino and M. Mabuchi "Enhanced stretch formability of $M g-A l-Z n$ alloy sheets rolled at high temperature" Scripta Materialia, vol. 60(2009), pp. 447-450.

[8] S.H. Zhang, K. Zhang, Y.C. Xu, Z.T. Wang “Deep-drawing of magnesium alloy sheets at warm temperatures" Journal of Materials Processing Technology, 185(2007),pp. 147-151

[9] K. Mori and H. Tsuji "Cold Deep Drawing of Commercial Magnesium Alloy Sheets" Journal of Japan The Technology of Plasticity, vol. 48, No. 552(2006), pp. 41-45.

[10] N. Koga, M. Asaka and K. Junlapen "Deep-drawing and ironing of 1050 aluminum sheets loaded with vibration using NC servo press machine" Journal of Japan Institute of Light Metals, vol. 57, No. 6(2007), pp. 240-244. 
[11] T. Jimma, Y. Kasuga, N. Iwaki, O. Miyazawa, E. Mori, K. Ito and H. Hatano "An Application of Ultrasonic Vibration to the Deep Drawing Process" Journal of Materials Processing Technology, vol. 80-81, (1998), pp. 406-412.

[12] S. Kataoka, J. Kihara, T. Aizawa, T. Nakada and K. Kato "Development of Deep Drawing Process with Hydraulic Counter Pressure and Vibration to Tool System" Journal of Japan the Technology of Plasticity, vol. 35, No. 403(1994), pp. 977-982.

[13] H. Yamashita, A. Ueno and H. Nakai "Technology to Enhance
Deep-drawability by Strain Dispersion Using Stress Relaxation Phenomenon" Honda R\&D technical review 24(1), pp. 142-148, 2012-04.

[14] T. Suganuma "Application to sheet drawing of servo press machine" Journal of Japan the Technology of Plasticity, vol. 49, No. 565(2008), pp. 118-122(in Japanese).

[15] B. D. Cullity, (1956), ELEMENTS OF X-RAY DIFFRACTION, United States of America: ADDISION-WESLYEY, pp. 84-85. 